\title{
On the functional degradation of binary titanium-tantalum high-temperature shape memory alloys - A new concept for fatigue life extension
}

\author{
T. Niendorf* ${ }^{\S}$, P. Krooß*, E. Batyrsina ${ }^{\dagger}$, A. Paulsen ${ }^{*}$, J. Frenzel ${ }^{\star}$, G. Eggeler ${ }^{\star}$ and H. J. Maier ${ }^{\dagger}$ \\ *Lehrstuhl für Werkstoffkunde (Materials Science) \\ University of Paderborn, 33098 Paderborn, Germany \\ $\dagger$ Institut für Werkstoffkunde (Materials Science) \\ Leibniz Universität Hannover, 30823 Garbsen, Germany \\ Institut für Werkstoffe, Ruhr-Universität Bochum \\ 44801 Bochum, Germany \\ 泣ndorf@lwk.upb.de
}

Received 26 March 2014; Accepted 29 March 2014; Published 12 May 2014

\begin{abstract}
High-temperature shape memory alloys are promising candidates for actuator applications at elevated temperatures. Ternary nickeltitanium-based alloys either contain noble metals which are very expensive, or suffer from poor workability. Titanium-tantalum shape memory alloys represent a promising alternative if one can avoid the cyclic degradation due to the formation of the omega phase. The current study investigates the functional fatigue behavior of Ti-Ta and introduces a new concept providing for pronounced fatigue life extension.
\end{abstract}

Keywords: Omega phase; martensite; phase transformation; microstructure; shape memory effect.

Conventional shape memory alloys (SMAs) have been intensely investigated over the last decades due to their extraordinary properties. ${ }^{1-6}$ Different metallic alloys can show a shape memory effect, e.g. Cu-based ${ }^{5}$ and Fe-based systems, ${ }^{6}$ but $\mathrm{Ni}-\mathrm{Ti}$ is still the most widely used conventional $\mathrm{SMA}^{3}$ due to good functional and structural properties. Unfortunately, the transformation temperatures of $\mathrm{Ni}-\mathrm{Ti}$ are limited to below $100^{\circ} \mathrm{C}$, thus hindering applications in elevated and high-temperature regimes. ${ }^{7}$ As shape memory actuators allow for designing devices characterized by high compactness and efficiency, a large effort has been spent to develop high-temperature shape memory alloys (HTSMAs). For actuation in a medium temperature range of about 100$400^{\circ} \mathrm{C}$, mainly $\mathrm{Ni}-\mathrm{Ti}$ based ternary $(\mathrm{Ni}-\mathrm{Ti}-\mathrm{X})$ systems have been proposed. ${ }^{8-10}$ These alloys show promising shape memory characteristics, i.e. actuation strain and microstructural stability, but at the same time suffer from two main drawbacks, i.e. poor workability and/or high amounts of noble metals. ${ }^{8,9,11}$

Titanium-tantalum SMAs represent a promising alternative to overcome all these issues if one can avoid the cyclic degradation due to the formation of the $\omega$-phase. The current

$\S_{\text {Corresponding author. }}$ study investigates the functional fatigue behavior of $\mathrm{Ti}-\mathrm{Ta}$ and introduces a new concept providing pronounced fatigue life extension. The cyclic deformation behavior of a polycrystalline titanium-tantalum (Ti-Ta) alloy containing 30 at.\% Ta under iso-stress loading during thermal cycling employing temperatures ranging from $50^{\circ} \mathrm{C}$ to $600^{\circ} \mathrm{C}$ was investigated. In order to reveal the most detrimental factor leading to a change of transformation temperatures and a loss of transformation strain, fatigue tests were conducted with differing heating and cooling rates and aging treatments. Using X-ray diffraction (XRD) it could be clearly shown that stabilization of the high-temperature parent phase ( $\beta$-phase) and the concomitant evolution of the $\omega$-phase led to functional degradation. The results of the current study suggest that both phases are mainly induced through aging during high temperature exposure and not by martensitic transformation events during cycling. A new concept employing single-step short-time annealing for regeneration of the initial transformation behavior is introduced.

As shown and intensively discussed in a series of studies published by Buenconsejio et al., ${ }^{12-14}$ the Ti-Ta system is characterized by relatively cheap alloying elements and excellent workability. It thus complies with demands of robust industrial applications. However, it has also been revealed 
that binary Ti-Ta alloys lack functional stability. ${ }^{12-14}$ This is attributed primarily to the formation of the $\omega$-phase, which is known to form in similar alloys like Ti-Nb, for example. ${ }^{12}$ Concomitant, the high-temperature parent $\beta$-phase in Ti-Ta alloys is stabilized down to lower temperatures and consequently hinders the shape memory effect. ${ }^{12-14}$ Ternary elements allow for improvement by delaying the formation of the $\omega$-phase, thus stabilizing the shape memory effect and its cycling behavior investigated up to 20 cycles. ${ }^{13,14}$ As functional fatigue and microstructural evolution are crucial factors for a sound understanding of the alloy performance, the current study addresses these issues, by employing heating and cooling rates differing by a factor of 75 in tests conducted at temperatures up to $600^{\circ} \mathrm{C}$ for up to 500 cycles. Microstructure analyses were performed to uncover the factors that govern functional degradation. Finally, a heat treatment process was established that leads to restoration of the initial properties eventually allowing for substantial fatigue life extension.

In the current study, dogbone-shaped tensile specimens with a nominal gauge length of $55 \mathrm{~mm}$ and a cross section of $1.5 \mathrm{~mm} \times 1.0 \mathrm{~mm}$ were prepared from polycrystalline Ti-Ta sheet material with 30 at. $\%$ Ta using electro-discharge machining (EDM). The Ti-Ta alloy was produced using high-purity Ti and Ta as raw materials for arc melting. After homogenization, annealing sheets were produced by rolling. The final recrystallization annealing was carried out at $900^{\circ} \mathrm{C}$ for $10 \mathrm{~min}$. The details on alloy preparation and processing are given elsewhere. ${ }^{15}$ The tensile samples were mechanically ground in order to remove surface layers resulting from EDM. For phase analyses and mechanical testing, the samples were mechanically ground down to a grit size of $5 \mu \mathrm{m}$ followed by vibro-polishing. The fatigue tests were carried out using a servo-hydraulic test rig. Tests were conducted under stress control employing loads ranging from 0 to $200 \mathrm{MPa}$. An induction heater was used for heating and temperatures were controlled using thermocouples which were fixed onto sample surfaces. In order to avoid any structural change, e.g. induced by spot welding, a thin copper wire was wound around the sample and the thermocouple in such a way that proper contact was ensured. Temperatures as well as thermal gradients were cross-checked by thermal imaging. The temperature gradient within the gauge length was always below $5^{\circ} \mathrm{C}$. Using this setup, heating rates of $0.33^{\circ} \mathrm{C} \mathrm{s}^{-1}$ and $25^{\circ} \mathrm{C} \mathrm{s}^{-1}$ were employed. Forced cooling was realized using compressed air. For the aging procedures, the samples were heated either load free in a conventional furnace or under a given mechanical load in the test rig. Preand post-fatigue phase analyses were done using XRD using a $\mathrm{Cu}$-K $\alpha$-source operating at $45 \mathrm{kV}$ and $40 \mathrm{~mA}$. For all XRD measurements, the sample surfaces were prepared as described above.

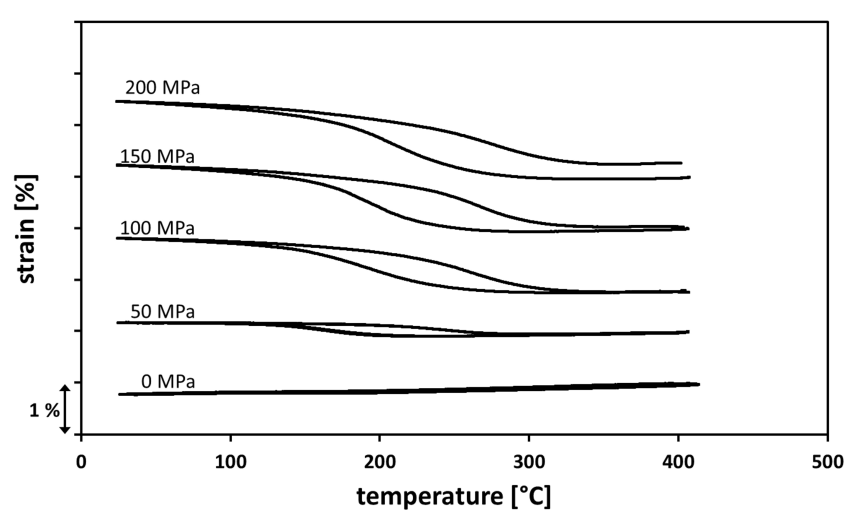

Fig. 1. Strain-temperature curves at heating rates of $25^{\circ} \mathrm{C} \mathrm{s}^{-1}$ for Ti-30Ta. Transformation strain becomes noticeable at a stress level of $50 \mathrm{MPa}$, and higher residual strains can be observed above $150 \mathrm{MPa}$.

Figure 1 shows strain-temperature curves for Ti-30Ta under different superimposed stresses. The curves are plotted with respect to relative strain. The tests were conducted in stress control with stress levels ranging from 0-200 MPa. At a low load level of $50 \mathrm{MPa}$, transformation strains are small. Transformation strains significantly increase at higher load levels, but for loads above $100 \mathrm{MPa}$, the presence of irreversible strains is clearly revealed. Consequently, all tests conducted in the remainder of this study were conducted at $100 \mathrm{MPa}$, as this is the optimum value with respect to transformation strain and reversibility of the martensitic transformation. In the following tests, the effects of different heating and cooling rates at a constant load level of $100 \mathrm{MPa}$ were considered. As has been described before, these rates differ by a factor of 75. Two sets of data are shown in Fig. 2. Figure 2(a) details the results employing slow heating/cooling rates (which are similar to those of the work of Buenconsejo et al. $\left.{ }^{12}\right)$.

As has been found previously, ${ }^{12}$ a rapid decrease of transformation temperatures can be found in the early stages of cycling. Buenconsejo et al. attributed this to the formation of the $\omega$-phase, ${ }^{12-14}$ which seems to evolve in the current material as well, as will be shown later. As can be deduced from Fig. 2(a), the current alloy almost fully lost its shape memory effect in the fourth cycle. This loss of functionality is well known for similar SMAs, e.g. Ti-Nb. ${ }^{12}$ As can be seen in Fig. 2(b) the evolution of transformation temperatures and transformation strains is qualitatively similar when heating and cooling rates are increased by a factor of 75 . It is important to note, however, that cycle numbers 1 to 500 are plotted in Fig. 2(b). Consequently, the number of cycles itself is not a key factor for the degradation behavior in Ti-Ta HTSMA, in contrast to what is known for other SMAs, e.g. Ni-Ti. Investigating the aging behavior in an interval ranging from $250^{\circ} \mathrm{C}$ to $700^{\circ} \mathrm{C}$, it is revealed that aging at temperatures in between $250^{\circ} \mathrm{C}$ and $400^{\circ} \mathrm{C}$ leads to a significant drop of the martensite 


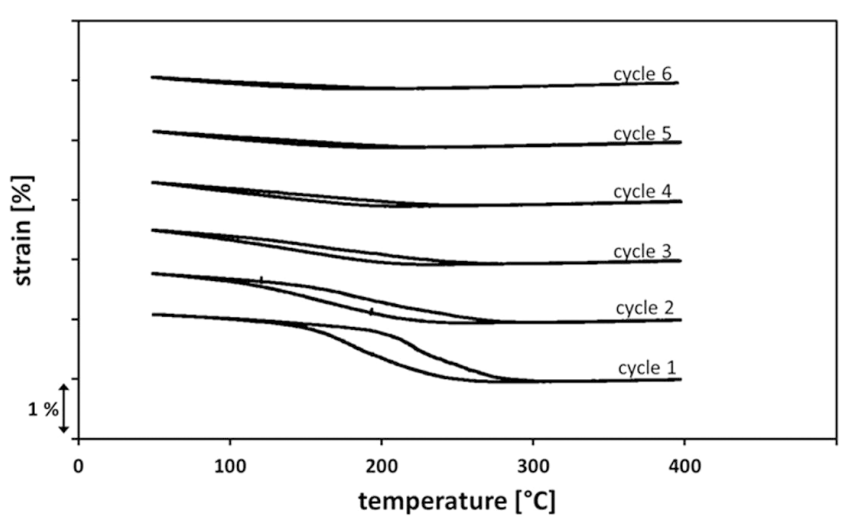

(a)

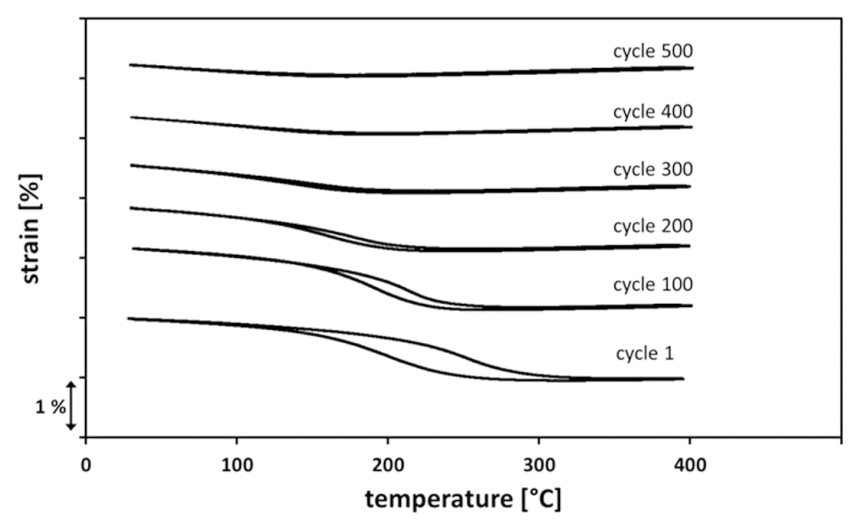

(b)

Fig. 2. Cyclic strain-temperature curves obtained for Ti-30Ta at heating rates of (a) $0.33^{\circ} \mathrm{C} \mathrm{s}^{-1}$ and (b) $25^{\circ} \mathrm{C} \mathrm{s}^{-1}$.

start temperature $\left(M_{S}\right)$. This is caused by the formation of the $\omega$-phase. ${ }^{12,15}$ Thus, the dwell time in the critical temperature regime, i.e. from $250^{\circ} \mathrm{C}$ to $400^{\circ} \mathrm{C}$ for the tests conducted in the current study, can be calculated for the curves shown in Fig. 2 . For the rate of $0.33^{\circ} \mathrm{C} \mathrm{s}^{-1}$, the dwell time is $15 \mathrm{~min}$ for each thermal cycle. For the higher rate the dwell time was found to be $12 \mathrm{~s}$ for a single cycle, which corresponds to $20 \mathrm{~min}$ when considering 100 heating-cooling cycles.

In order to reveal the effect of dwell time, additional tests have been conducted employing artificial aging following the first thermomechanical cycle. Figure 3 shows the effects of both, cycling and constant temperature aging, on the straintemperature curves. The first cycle of the initial material state (Fig. 3 lower part) corresponds to what is observed for the asprocessed Ti-Ta, Fig. 1. Next, the specimen was aged at $350^{\circ} \mathrm{C}$ for $20 \mathrm{~min}$ under a constant load of $100 \mathrm{MPa}$. The parameters have been chosen based on the critical

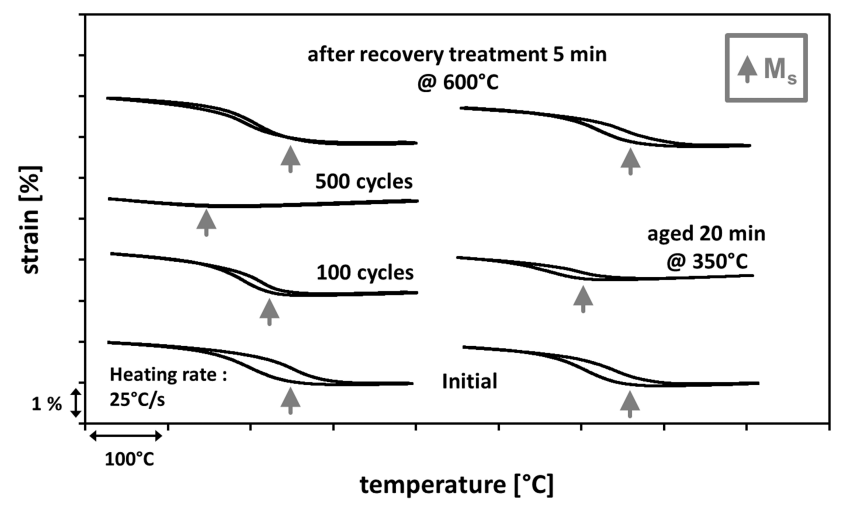

Fig. 3. Strain-temperature curves for Ti-30Ta following different treatments. The initial cycles shown at the bottom depict the behavior of the asprocessed condition. Evolution of $M_{S}$ is schematically indicated by the bold gray arrows. Following 100 cycles and $20 \mathrm{~min}$ artificial aging the transformation strain is very similar indicating the dominant effect of dwell time. Concurrently, $M_{S}$ is shifted to a lower value in the aged Ti-Ta. Through short time recovery treatment strain capability and $M_{S}$ are restored as shown by the curves in the upper part of the diagram. temperature range and dwell times discussed above. The first cycle following this heat treatment (Fig. 3 right-hand side) shows a strain-temperature curve which is similar to the curve obtained after fatigue for 100 cycles, employing the high heating rate shown in Figs. 2 and 3 (left-hand side). For both conditions, martensite start temperatures (indicated by arrows in Fig. 3), and transformation strains are strongly affected. In comparison to the samples that were exposed to thermomechanical cycling, functional degradation seems to evolve slightly faster in the aging experiment. Consequently, the $\omega$-phase formation is almost solely influenced by the dwell time in a critical temperature range with the most detrimental temperatures being around $350^{\circ} \mathrm{C}$. Buenconsejo et al. report similar trends following aging, but in their study they conducted aging at lower temperatures using a Ti-Ta alloy with a different composition. ${ }^{12}$

In a subsequent step, the samples have been heat treated at a higher temperature of $600^{\circ} \mathrm{C}$ for very short times, i.e. ranging from 1 to $5 \mathrm{~min}$. This type of short time treatment has been proposed for functional optimization of $\mathrm{Ti}-\mathrm{Nb}$ alloys, but that case was aiming at property optimization with respect to superelasticity at room temperature. ${ }^{16,17}$ In the current study, the heat treatment of the Ti-Ta samples was performed with a different objective in mind. As shown in Fig. 3 (upper part), the functionally degraded specimens fully recover their initial transformation strain ability of about $1 \%$. Concurrently, $M_{S}$ is shifted toward its initial value, i.e. to higher temperatures. The same finding was obtained for all other degraded conditions, i.e. irrespective of the heating rate used (c.f. Fig. 2). The minor differences in hysteresis shape are currently under investigation. The recovery of the functional properties eventually will allow for substantial extension of the fatigue life of Ti-Ta HTSMAs.

For better understanding of microstructure evolution upon aging and recovery treatment, XRD phase analyses were carried out at room temperature. Results for representative 


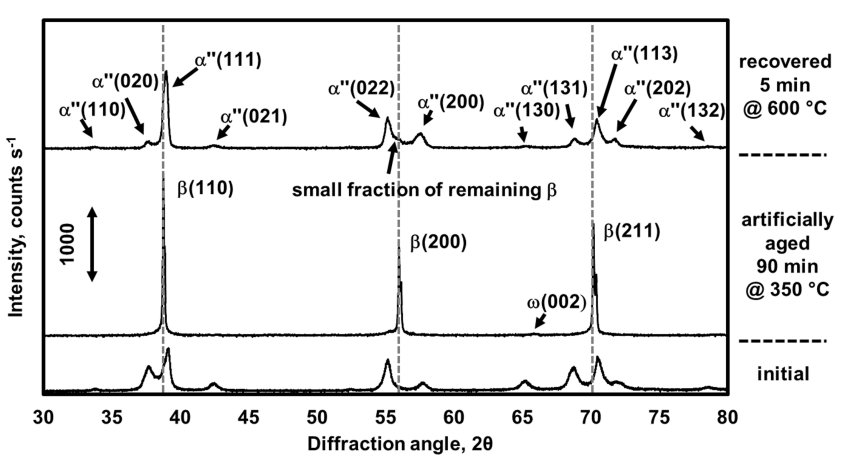

Fig. 4. XRD profiles showing relative intensities at room temperature for Ti-30Ta in different conditions. The as-processed condition and the condition following recovery treatment depict a martensitic state, whereas the artificially aged condition is characterized by high intensity peaks from the $\beta$-phase.

samples from Figs. 2 and 3 are shown in Fig. 4. The asprocessed Ti-Ta is characterized by a fully martensitic $\alpha^{\prime \prime}$ microstructure in accordance with data from literature. ${ }^{12}$ Irrespective of the actual fatigue testing procedure, i.e. thermal cycling or artificial aging in the critical temperature regime, the microstructure changed in a similar way. The presence of the $\omega$-phase can be revealed for all thermally loaded specimens, but due to the small volume fraction of the $\omega$-phase particles, the intensity of the peaks remains small. In addition, the $\beta$-phase is stabilized in all fatigued samples. The similarity of the XRD diffractograms suggests a similar microstructural evolution in all specimens. As a consequence of $\beta$-phase stabilization, the Ti-Ta samples tested under different loading sequences degrade and eventually lose their functionality. Clearly, such kind of microstructural and functional degradation needs to be kept at a minimum for applications of Ti-Ta HTSMA. As has already been shown by Buenconsejo et al. ternary elements, e.g. aluminum and tin, are suitable means to hamper $\omega$-phase formation. ${ }^{13,14}$ Using short time recovery, the current study introduces an alternative approach for property optimization, especially with respect to fatigue life extension. The concept can be easily implemented in actuator applications. The short time recovery treatment results in restoration of the initial transformation strain capability. The effect of the short time recovery annealing is attributed to dissolution of $\omega$-phase, which eventually resets $\beta$-phase stabilization.

The functional fatigue behavior of a binary Ti-Ta alloy was investigated in the current study. By employing different testing parameters, new insights into the mechanisms governing the cyclic degradation of Ti-Ta HTSMA were obtained. Especially the influence of heating-cooling rates and dwell times in a critical temperature interval has been revealed. In addition, a recovery treatment has been proposed leading to significant fatigue life extension.

The main conclusions from the results obtained in the present work can be summarized as follows:

(1) Cyclic degradation of Ti-Ta HTSMAs is due to $\omega$-phase formation and stabilization of the $\beta$-parent-phase.

(2) The most important factor for degradation of the Ti-Ta binary alloy is the dwell time spent in the temperature window ranging from about $250^{\circ} \mathrm{C}$ to $400^{\circ} \mathrm{C}$. This is due to intense $\omega$-phase formation occurring exclusively in this region.

(3) A short time annealing at a temperature of $600^{\circ} \mathrm{C}$ allows for full restoration of the initial transformation strain capability of the Ti-Ta binary alloy.

\section{Acknowledgment}

This work was supported by Deutsche Forschungsgemeinschaft within the Research Unit Program "HochtemperaturFormgedächtnislegierungen" (Contract Nos. NI1327/3-1; MA1175/34-1; FR2675/3-1).

\section{References}

1. K. Otsuka and X. Ren, Prog. Mater. Sci. 50, 511 (2005).

2. E. Hornbogen and W. G. J. Bunk (eds.), Advanced Structural and Functional Materials (Springer, Heidelberg, 1991), pp. 133-163.

3. N. B. Morgan, Mater. Sci. Eng. A 378, 16 (2004).

4. J. Frenzel et al., Acta Mater. 58, 3444 (2010).

5. Y. Sutou et al., Acta Mater. 57, 5759 (2009).

6. P. Krooß et al., Funct. Mater. Lett. 5, 1250045 (2012).

7. J. Ma et al., Int. Mater. Rev. 55, 257 (2010).

8. J. Monroe et al., Scr. Mater. 65, 123 (2011).

9. K. C. Atli et al., Scr. Mater. 64, 315 (2011).

10. H. Karaca et al., Acta Mater. 61, 7422 (2013).

11. M. Belbasi et al., Mater. Sci. Eng. A 560, 96 (2013).

12. P. J. S. Buenconsejo, H. Y. Kim, H. Hosoda and S. Miyazaki, Acta Mater. 57, 1068 (2009).

13. P. J. S. Buenconsejo, H. Y. Kim and S. Miyazaki, Acta Mater. 57, 2509 (2009).

14. P. J. S. Buenconsejo, H. Y. Kim and S. Miyazak, Scr. Mater. 64, 111 (2011).

15. J. Zhang et al., Int. J. Mater. Res. 105, 156 (2014).

16. F. Sun et al., Scr. Mater. 63, 1053 (2010).

17. F. Sun et al., J. Mech. Beh. Biomed. Mater. 4, 1864 (2011). 